Article

\title{
Precise Orbit Determination of BeiDou Satellites with Contributions from Chinese National Continuous Operating Reference Stations
}

\author{
Ming Chen ${ }^{1,2,4}$, Yang Liu ${ }^{3,4, *}$, Jiming Guo ${ }^{1, *}$, Weiwei Song ${ }^{3,4}$, Peng Zhang ${ }^{2,4}$, Junli Wu ${ }^{2,4}$ and \\ Di Zhang ${ }^{1}$ \\ 1 School of Geodesy and Geomatics, Wuhan University, Wuhan 430079, China; cm@ngcc.cn (M.C.); \\ zhangdi@whu.edu.cn (D.J.) \\ 2 National Geomatics Center of China, Beijing 100830, China; zhangpeng@ngcc.cn (P.Z.); jlwu@ngcc.cn (J.W.) \\ 3 GNSS Research Center, Wuhan University, Wuhan 430079, China; SWW@whu.edu.cn \\ 4 Key Laboratory of Navigation \& Location Based Service, National Administration of Survey, \\ Mapping and Geoinformation, Beijing 100830, China \\ * Correspondence: liudaweng@whu.edu.cn (Y.L.); jmguo@sgg.whu.edu.cn (J.G.); \\ Tel.:+86-027-6877-7305 (Y.L.); +86-027-6877-8807 (J.G.)
}

Received: 30 June 2017; Accepted: 4 August 2017; Published: 6 August 2017

\begin{abstract}
The precise orbit determination (POD) for BeiDou satellites is usually limited by the insufficient quantity and poor distribution of ground tracking stations. To cope with this problem, this study used the GPS and BeiDou joint POD method based on Chinese national continuous operating reference stations (CNCORS) and IGS/MGEX stations. The results show that the 3D RMS of the differences of overlapping arcs is better than $22 \mathrm{~cm}$ for geostationary orbit (GEO) satellites and better than $10 \mathrm{~cm}$ for inclined geosynchronous orbit (IGSO) and medium earth orbit (MEO) satellites. The radial RMS is better than $2 \mathrm{~cm}$ for all three types of BeiDou satellites. The results of satellite laser ranging (SLR) residuals show that the RMS of the IGSO and MEO satellites is better than $5 \mathrm{~cm}$, whereas the GEO satellite has a systematic bias. This study investigates the contributions of CNCORS to the POD of BeiDou satellites. The results show that after the incorporation of CNCORS, the precision of overlapping arcs of the GEO, IGSO, and MEO satellites is improved by $15.5 \%, 57.5 \%$, and $5.3 \%$, respectively. In accordance with the improvement in the precision of overlapping arcs, the accuracy of the IGSO and MEO satellites assessed by the SLR is improved by $30.1 \%$ and $4.8 \%$, respectively. The computation results and analysis demonstrate that the inclusion of CNCORS yields the biggest contribution in the improvement of orbit accuracy for IGSO satellites, when compared to GEO satellites, while the orbit improvement for MEO satellites is the lowest due to their global coverage.
\end{abstract}

Keywords: precise orbit determination; ground tracking stations; BeiDou satellites; Chinese national continuous operating reference stations

\section{Introduction}

The regional system construction of the BeiDou navigation satellite system (BDS) was completed by the end of 2012, accomplishing the second step of the construction task of the "three steps" strategy. The system has positioning, navigation, timing, and short-message communication service capabilities covering the Asia-Pacific region. The satellites in orbit include five geostationary orbit (GEO), five inclined geosynchronous orbit (IGSO), and four medium earth orbit (MEO) satellites. BeiDou satellites have been continuously launched in recent years, and the BDS, which comprises 35 satellite constellations with global coverage, is targeted for completion by 2020 [1].

A series of studies have been carried out on the precise orbit determination (POD) of BeiDou satellites. Currently, BeiDou satellite orbits have a 3D precision of about $10-30 \mathrm{~cm}$ for IGSO and 
MEO satellites and about 3-4 m for BeiDou GEO satellites based on ground tracking stations [2-16]. As a secondary orbit determination system, on-board GPS-based orbit determination in GEO can demonstrate a 3D positioning accuracy of about $1 \mathrm{~m}$ [17]. Several factors affect the precision of BeiDou POD, such as satellite orbit dynamic modeling, solar radiation pressure $[2,5,6,10,14-16]$, albedo and antenna thrust, satellite attitude and maneuver [18-21], and transmitting antenna phase center modeling [22]. Besides the factors mentioned above, the orbit determination method, as well as the number and distribution of ground tracking stations, play an important role in BeiDou orbit determination. In terms of the orbit determination method, Ge et al. [2] analyzed the BDS single-system independent orbit determination method and found that the precisions of 3D overlapping arcs of GEO and IGSO satellites reached 3.3 and $0.5 \mathrm{~m}$, respectively. Based on the two-step GPS-assisted BeiDou orbit determination method, Shi et al. [3] achieved a radial overlap precision at the $0.1 \mathrm{~m}$ level for both BeiDou GEO and IGSO satellites. Liu et al. [8] adopted the BDS/GPS joint orbit determination method. The 3D overlap precision of the GEO, IGSO, and MEO satellites reached 155, 33, and $28 \mathrm{~cm}$, respectively, and the radial overlap precision was basically better than $10 \mathrm{~cm}$. Lou et al. [11] studied the precision differences of the BDS single-system orbit determination method and the GPS-assisted two-step orbit determination method, as well as the causes of such differences. In terms of the number and distribution of ground tracking stations, He et al. [9] conducted several experiments on the impact of expanding the tracking geometry and the addition of MEO satellites on the BeiDou precise orbit. They concluded that expanding the geometry contributes to improving the BeiDou orbit's precision. Using the BeiDou Experimental Tracking Stations (BETS) and the International GNSS Service (IGS) Multi-GNSS Experiment (MGEX) network stations for BeiDou orbit determination, Lou et al. [10] obtained an IGSO and MEO satellite orbit precision of 10-20 cm and GEO satellite orbit precision of several meters, and satellite laser ranging (SLR) residuals were better than $10 \mathrm{~cm}$ for IGSO/MEO and several decimeters for GEO satellites. Zhang et al. [12] analyzed the impact of the distribution of ground tracking stations on the BeiDou POD by means of satellite position dilution of precision. The number and distribution of ground tracking stations are important factors influencing the precision of orbit determination. With the development of the BeiDou constellation, domestic and international organizations have accelerated the construction of BeiDou stations. In 2011, the MGEX project of IGS began researching several satellite systems, including the tracking and analysis of BeiDou signals [23]. At present, more than 100 stations in the MGEX project are able to receive BeiDou signals, and the distribution of stations has become more reasonable. In China, the National Administration of Surveying, Mapping and Geoinformation organized the construction of Chinese national continuous operating reference stations (CNCORS), and 360 stations have been evenly established throughout the country [24]. Of this number, 210 stations are able to receive data from four global navigation satellite systems, thereby providing continuous data for BeiDou orbit determination and positioning, as well as other related studies.

This study aims to obtain the latest results of the BeiDou POD, and investigate the impact of the CNCORS on BeiDou precise orbits. Firstly, the BeiDou orbit determination method, the observation model, and the orbit dynamic model are introduced. Then, the accuracy of the BeiDou precise orbit based on different ground tracking stations is analyzed and compared, providing the results of the BeiDou precise orbits based on the current CNCORS and MGEX stations. We studied the influence of the CNCORS on BeiDou POD and the precision difference between the BDS single-system independent POD and the BDS/GPS joint POD. We also analyzed the orbit determination precision regarding the different tracking station distributions based on the orbit dilution of precision(ODOP). We compared the experimental results with the results of previous studies. Finally, the experimental results are discussed and summarized.

The paper is organized as follows: data collection and processing methods are firstly described in Section 2. In Section 3, the results of the orbit precision comparison and satellite laser ranging (SLR) assessment for different strategies are derived. The results of experimental data are analyzed and discussed in Section 4. Conclusions are given in Section 5. 


\section{Materials and Methods}

Position And Navigation Data Analyst (PANDA) software [25] is used in this study for the computation of the BeiDou precise orbit. PANDA is a multifunctional software developed by Wuhan University that is capable of conducting multi-system precise orbit determination, positioning, and atmospheric studies. Generally, the BeiDou POD method mainly includes BDS single-system and BDS/GPS joint orbit determination. The BDS single-system orbit determination solely uses the BeiDou observation data to solve the BeiDou satellite orbit, satellite clock, tropospheric delay, receiver clock error, and other parameters. The joint orbit determination method utilizes both GPS and BeiDou observation data of the ground stations to solve the GPS and BeiDou satellite orbit, satellite clock error, tropospheric delay, receiver clock error, and inter-system biases in a combination fashion.

The method for satellite orbit determination mainly includes the choice of observation model parameters, the error correction model, and the satellite dynamic model. Important options of the considered processing methods for the observation model and for the forces model [11] are listed in Tables 1 and 2.

Table 1. Observation model and configuration of parameters.

\begin{tabular}{ll}
\hline \multicolumn{1}{c}{ Parameter } & \multicolumn{1}{c}{ Model } \\
\hline Preprocessing & Automatic edition of single-station data \\
Observation data & Undifferenced iono-free code and phase combination of L1/L2 and B1/B2, \\
higher-order ionospheric delay not considered \\
Sample rate & $300 \mathrm{~s}$ \\
Cutoff elevation angle & $7^{\circ}$ \\
Weight & Priori precision of 0.01 cycle phase and 0.5 m code. When the elevation angle is $>30^{\circ}$, \\
Phase windup & the weight is 1; otherwise $2 \times \sin (\mathrm{E})$ \\
Inter-system bias & Considered \\
Phase center model & Constant parameters estimated using the zero mean datum constraint conditions \\
Tropospheric delay & igs08.atx \\
Satellite and receiver clock & GPT model [26], GMF mapping function [27], 2-hourly wet delay estimation \\
Station coordinates & White noise \\
ERP & Fixed to GPS precise point positioning \\
\hline & Estimate the polar motion $x, y$ components and its rates; fix UT1 and estimate its rate. \\
\hline
\end{tabular}

Table 2. Satellite force model.

\begin{tabular}{cc}
\hline Name & Model \\
\hline Earth Gravity & EGM2008 up to 12 $\times 12$ \\
N-body gravitation & Sun, moon, and other planets (DE405) \\
Tides & Solid tide, ocean tide, polar tide \\
Solar radiation pressure & ECOM five parameters [28] \\
Relativity effect & IERS Convention 2010 \\
Albedo and antenna thrust model & Considered for GPS only \\
\hline
\end{tabular}

The POD of navigation satellites mainly includes the acquisition of satellite orbit initial conditions, the orbit integration, the reduction and linearization of observation data, and the formation and solution of the normal equation. Firstly, the observation data of ground tracking stations are preprocessed. After the outliers' detection and removal, in addition to the cycle slips' marking, the LC and PC observations are combined. Orbit integration of the broadcast ephemeris is performed to obtain the initial orbit solution of the satellite. Then, the parameters are initialized; the observation equation is formed using the satellite initial orbit, the dynamic model, and the observations. The unknown parameters in the least square estimation are the initial satellite position and velocity, solar radiation parameters, satellite clock errors, zenith tropospheric delay corrections, receiver clock errors, inter-system biases, and ambiguities. Finally, the least squares estimation is used to obtain corrections of the initial satellite orbit, and the satellite orbit parameters are integrated to obtain the orbit products. This is an iterative process, which means that orbit integration and parameter 
estimation using the orbit initial conditions are performed iteratively until the satellite orbit accuracy meets the requirements.

For the current BeiDou regional navigation system, GEO satellites remain in an area with a small range, whereas IGSO satellites fly within a specific longitude range. The solution of the long arcs of the BeiDou satellite can be stable. Therefore, unlike the GPS one-day arc orbit determination, this study uses the three-day arc for BeiDou satellite orbit determination. The computation process of the three-day solution of the BeiDou satellite orbit is slightly different from that of the one-day solution. The three-day solution needs to combine the observation data of ground tracking stations and broadcast ephemeris over three consecutive days, whilst the other computation steps are identical to those of the one-day solution.

A total of 124 stations were selected for POD to conduct a comprehensive analysis of the three types of satellite orbits of BeiDou, GEO, IGSO, and MEO. The 124 BDS/GPS stations include 24 CNCORS and 100 MGEX stations. The observation period was from 16 July 2016 to 2 August 2016.

Eight types of GNSS receiver equipment at the 124 ground stations are listed in Table 3. Of this number, 24 CNCORS stations are equipped with the Trimble NETR9 receiver and the chock-ring antenna, which are able to receive observation data from both GPS and BDS satellites.

Table 3. Tracking station receiver type and number.

\begin{tabular}{ccc}
\hline No. & Receiver Type & Number \\
\hline $\mathbf{1}$ & Trimble NETR9 & 86 \\
$\mathbf{2}$ & Septentrio POLARX4TR & 7 \\
$\mathbf{3}$ & Septentrio POLARX4 & 9 \\
$\mathbf{4}$ & Septentrio POLARX3/XS & 2 \\
$\mathbf{5}$ & LEICA GR25 & 10 \\
$\mathbf{6}$ & LEICA GR10 & 6 \\
$\mathbf{7}$ & LEICA GRX1200+ & 1 \\
$\mathbf{8}$ & JAVAD TRE_G3TH DELTA & 3 \\
Sum & & 124 \\
\hline
\end{tabular}

This study adopts the following four computation strategies to conduct the BeiDou orbit determination and analyze the influence of ground station distribution and multi-system joint processing on the accuracy of BeiDou orbit determination. The specific strategies are as follows:

Strategy 1: BDS/GPS joint orbit determination method. The ground station uses observation data from the 124 stations, including the CNCORS and MGEX stations. The ground station distribution is shown in Figure 1.

Strategy 2: BDS/GPS joint orbit determination method. The ground station uses data from the MGEX stations only, which means that the CNCORS stations are excluded.

Strategy 3: BDS Single-system orbit determination method. The ground station distribution is the same as that in strategy 1.

Strategy 4: BDS Single-system orbit determination method. The ground station distribution is the same as that in strategy 2. 


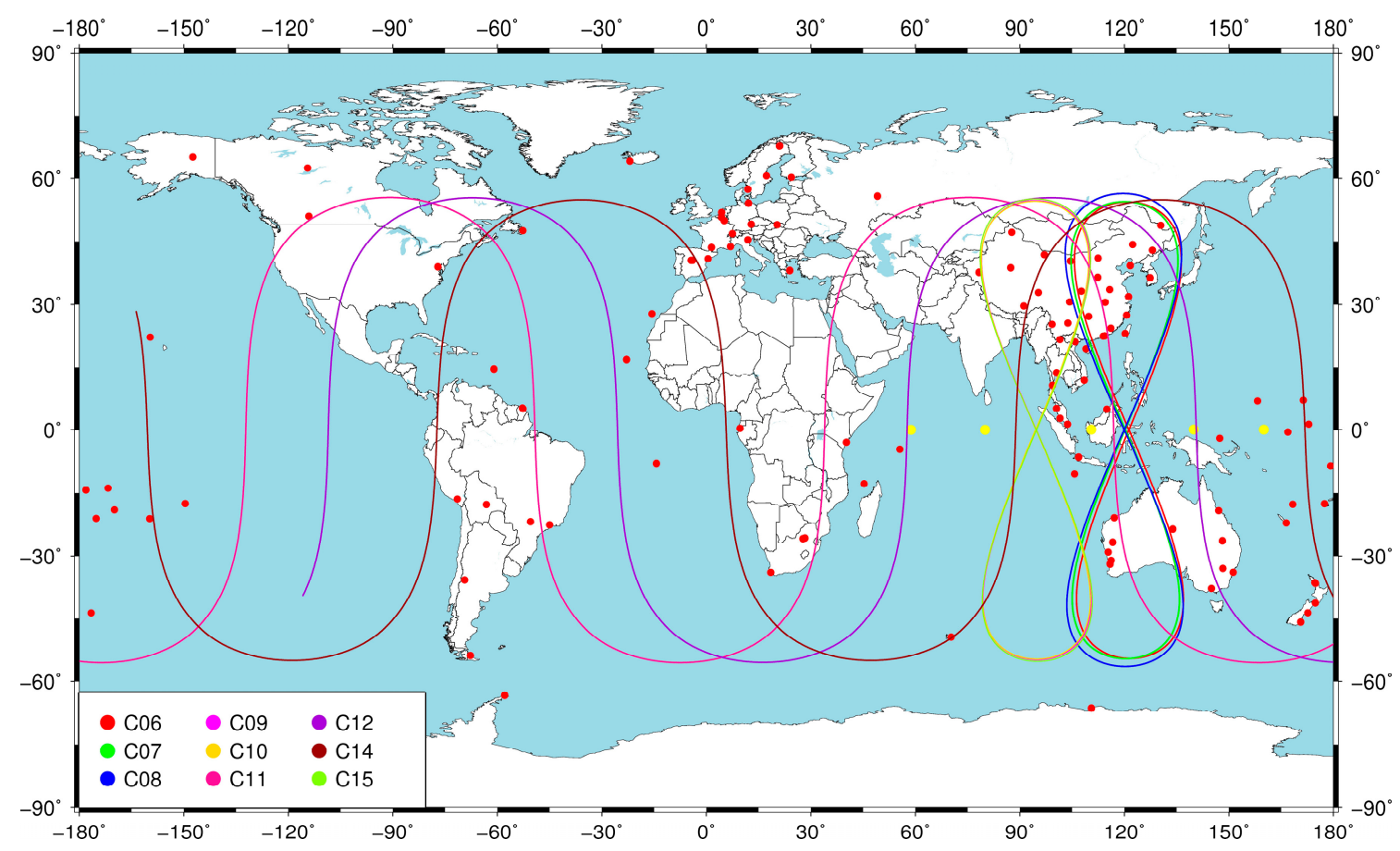

Figure 1. Ground traces of BeiDou satellites and tracking stations. Note 1: The red points indicate the ground stations with BDS/GPS tracking capability. The five yellow points near the equator are the five BeiDou GEO satellites; Note 2: The PRN of the original C15 satellite was changed to C13 on 11 December 2016. Given that this change was not made when this paper was written, C15 is still used to represent the PRN of this IGSO satellite. This figure is drawn using GMT software [29].

\section{Results}

This study uses the following three criteria to assess orbit precision: (1) Overlapping arcs for internal consistency [2,11]. The precision evaluation of the overlapping arcs is conducted using the consecutive three-day arc orbit solutions. The orbit of the last day of the first three-day solution and the orbit of the middle day of the second three-day solution are compared; (2) Comparison with the GBM multi-GNSS orbit products from the GFZ analysis center [13], which can be download from the FTP web site (ftp:/ / cddis.gsfc.nasa.gov/pub/gps/products/mgex/); (3) SLR independent accuracy assessment for external validation [30,31]. SLR retro-reflector offsets for these satellites are given at (https:/ /ilrs.cddis.eosdis.nasa.gov/missions/satellite_missions / current_missions/cmg1_ com.html) on the ILRS website [31]. The SLR station coordinates are fixed to the a priori SLRF2008. The station displacement models are applied consistently with the GNSS solutions. The troposphere delays, relativistic effects, and the offset of the LRAs with respect to the satellites' centers of mass are corrected in the SLR observations [30]. The two-step data screening procedures are employed for SLR processing [30]. A comparison of the four strategies using the above three criteria is shown below to verify the influence of the ground station distribution and joint orbit determination strategy on the BeiDou POD.

\subsection{Impact of CNCORS on BDS/GPS Joint POD}

Strategies 1 and 2 are compared to verify the contribution of Chinese regional stations to the BDS/GPS joint POD.

\subsubsection{Overlapping Arcs Precision}

The BeiDou POD is conducted according to strategies 1 and 2 based on the BDS/GPS joint orbit determination method. The mean RMS values of the overlapping arcs are shown in Table 4 and 
Figure 2. Table 4 and Figure 2 show that when MGEX and CNCORS are used as ground stations, the precision of the orbit overlapping arcs (3DRMS) is as follows: the average precision of GEO satellites is $17.2 \mathrm{~cm}$, that of IGSO satellites is $4.9 \mathrm{~cm}$, and that of MEO satellites is $5.6 \mathrm{~cm}$. The IGSO satellites have the best internal precision, and the reason for this is that more ground stations exist in the IGSO satellite coverage area and these evenly distributed stations provide observations for the IGSO satellite for a long time.

Table 4. Comparison of overlapping arcs precision between strategies 1 and 2 (unit: $\mathrm{cm}$ ).

\begin{tabular}{|c|c|c|c|c|c|c|c|c|c|}
\hline \multirow{2}{*}{ Satellite Type } & \multirow{2}{*}{ PRN } & \multicolumn{2}{|c|}{ Along-Track } & \multicolumn{2}{|c|}{ Cross-Track } & \multicolumn{2}{|c|}{ Radial } & \multicolumn{2}{|c|}{$3 \mathrm{D}$} \\
\hline & & S1 & $\mathrm{S} 2$ & S1 & S2 & S1 & S2 & S1 & $\mathrm{S} 2$ \\
\hline \multirow{6}{*}{ GEO } & C01 & 21.6 & 21.5 & 1.4 & 1.5 & 1.0 & 1.1 & 21.7 & 21.8 \\
\hline & $\mathrm{C} 02$ & 20.9 & 24.5 & 2.0 & 2.3 & 1.6 & 1.7 & 21.4 & 24.8 \\
\hline & $\mathrm{C} 03$ & 11.1 & 16.0 & 1.5 & 2.2 & 2.3 & 2.4 & 12.2 & 16.8 \\
\hline & $\mathrm{C} 04$ & 19.2 & 21.0 & 1.3 & 1.4 & 1.5 & 1.7 & 19.6 & 21.4 \\
\hline & C05 & 10.4 & 14.0 & 2.3 & 2.2 & 1.2 & 1.4 & 11.1 & 14.4 \\
\hline & Mean & 16.6 & 19.4 & 1.7 & 1.9 & 1.5 & 1.7 & 17.2 & 19.8 \\
\hline \multirow{7}{*}{ IGSO } & $\mathrm{C} 06$ & 3.2 & 5.2 & 2.8 & 3.9 & 1.6 & 2.1 & 4.8 & 7.0 \\
\hline & $\mathrm{C} 07$ & 3.6 & 5.8 & 2.7 & 4.4 & 2.3 & 2.8 & 5.8 & 8.7 \\
\hline & $\mathrm{C} 08$ & 3.0 & 4.7 & 2.7 & 3.8 & 1.8 & 2.3 & 4.5 & 6.6 \\
\hline & $\mathrm{C} 09$ & 2.7 & 6.5 & 3.1 & 5.5 & 1.7 & 2.7 & 4.6 & 8.6 \\
\hline & C10 & 2.8 & 5.5 & 2.6 & 4.3 & 2.0 & 3.0 & 4.5 & 7.9 \\
\hline & C15 & 3.3 & 4.6 & 3.3 & 4.1 & 1.9 & 2.2 & 5.2 & 7.4 \\
\hline & Mean & 3.1 & 5.4 & 2.9 & 4.3 & 1.9 & 2.5 & 4.9 & 7.7 \\
\hline \multirow{4}{*}{$\mathrm{MEO}$} & C11 & 4.1 & 4.4 & 2.4 & 2.0 & 1.3 & 1.3 & 5.7 & 5.1 \\
\hline & C12 & 4.5 & 5.7 & 2.7 & 2.6 & 1.7 & 1.7 & 5.7 & 6.7 \\
\hline & C14 & 3.3 & 4.6 & 2.4 & 3.1 & 1.5 & 1.6 & 5.4 & 5.9 \\
\hline & Mean & 4.0 & 4.9 & 2.5 & 2.6 & 1.5 & 1.5 & 5.6 & 5.9 \\
\hline
\end{tabular}

Among the three directions of the orbit, all the radial direction precisions of the three types of satellites are better than $2.3 \mathrm{~cm}$, the cross-track direction is better than $3.3 \mathrm{~cm}$, and the along-track direction for IGSO and MEO satellites is better than $4.5 \mathrm{~cm}$. The along-track direction for GEO satellites is poor, and the mean RMS value reaches $16.6 \mathrm{~cm}$. Thus, it can be seen that the precision of the BeiDou satellite orbit can reach a high level if the ground stations are evenly distributed. GEO satellites have a large along-track error due to their stationary nature, and the along-track component of the GEO satellite orbit is strongly correlated with other parameters.

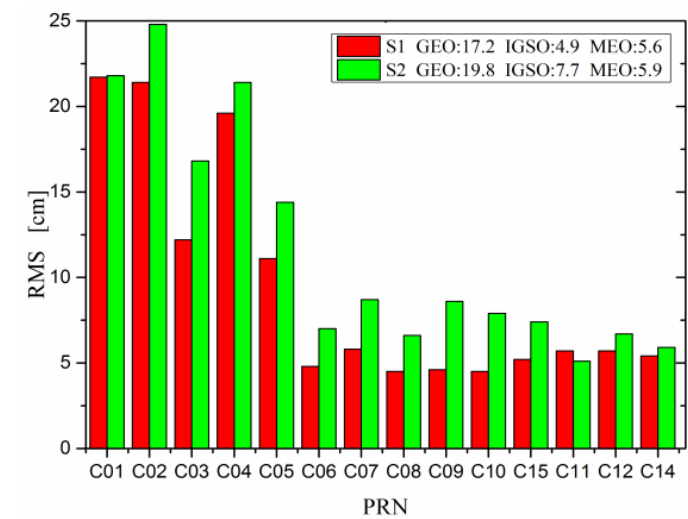

(a)

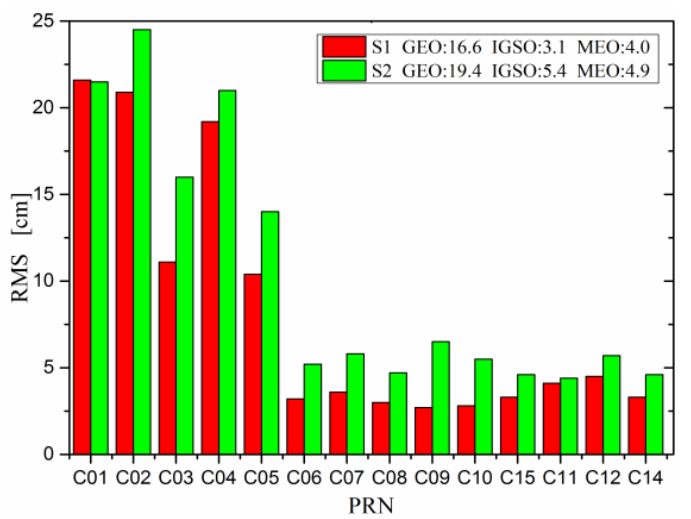

(b)

Figure 2. Cont. 


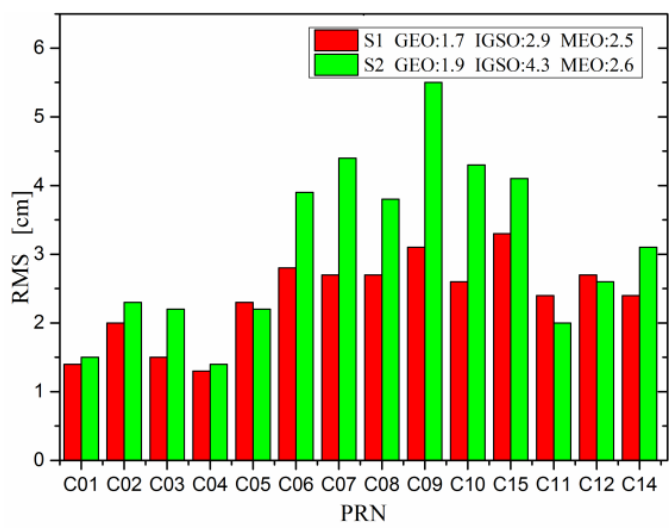

(c)

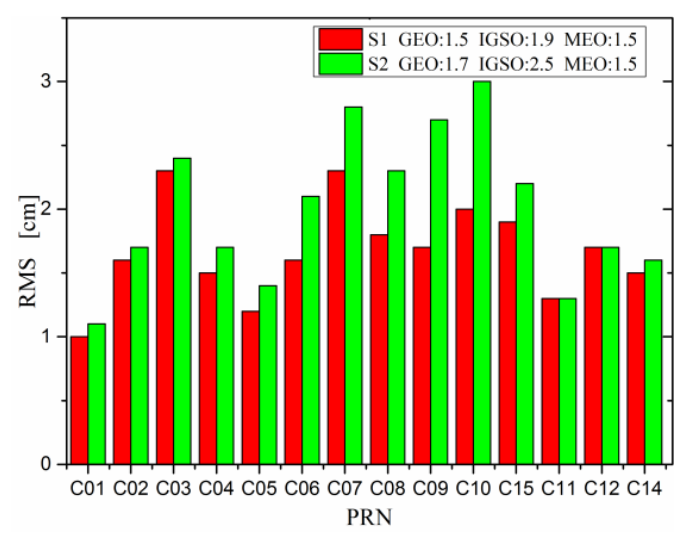

(d)

Figure 2. Comparison of overlapping arcs precision between strategies 1 and 2. (a) 3DRMS; (b) Along-track RMS; (c) Cross-track RMS; (d) Radial RMS.

The influence of the CNCORS on the POD of the BeiDou satellite can be obtained according to the comparison of the orbit determination precision in strategies 1 and 2. Figure 2 shows that the orbit precision of GEO and IGSO satellites in strategy 1 is better than that in strategy 2 . In addition, after the addition of the CNCORS, the 3D precision of GEO and IGSO satellites increased by $13.1 \%$ and $36.4 \%$, respectively. These results show that the CNCORS strongly influence the orbit precision of these two types of satellites, especially IGSO satellites, because the main coverage regions of the GEO and IGSO satellites are near the longitude in China. Given that the orbit of the IGSO satellites is close to the shape of a figure of " 8 " and the southern hemisphere has many stations, the station distribution in the whole orbit arc of the IGSO satellites is even, and its precision accordingly experiences the most improvement after adding the stations. However, MEO satellites operate globally, and after adding the CNCORS, the precision is improved by only $5.1 \%$. Therefore, the CNCORS exert a limited influence on the MEO orbit precision.

\subsubsection{Comparison with GBM Orbit}

BeiDou orbits from strategies 1 and 2 are compared with the GBM products. The results in Table 5 show that the precision of the overlapping arcs is not the same as the comparison with GBM. The results in the cross-track direction vary significantly. The average difference of the GEO satellites exceeds $3 \mathrm{~m}$. The difference of strategy 1 from the GBM products in all three directions is also larger compared to strategy 2. These results occurred because, similar to strategy 2, the GBM POD adopts few stations in China; therefore, the difference between the orbit results and strategy 2 is relatively small. Given the use of more stations, the precision of the POD in strategy 1 should be improved.

Table 5. Comparison with GBM orbit from strategies 1 and 2 (unit: $\mathrm{cm}$ ).

\begin{tabular}{|c|c|c|c|c|c|c|c|c|c|}
\hline \multirow{2}{*}{ Satellite Type } & \multirow{2}{*}{ PRN } & \multicolumn{2}{|c|}{ Along-Track } & \multicolumn{2}{|c|}{ Cross-Track } & \multicolumn{2}{|c|}{ Radial } & \multicolumn{2}{|c|}{$3 \mathrm{D}$} \\
\hline & & S1 & S2 & S1 & S2 & S1 & S2 & S1 & S2 \\
\hline \multirow{6}{*}{ GEO } & $\mathrm{C} 01$ & 217.5 & 227 & 287.3 & 287.8 & 11.5 & 10.8 & 369.6 & 376.8 \\
\hline & $\mathrm{C} 02$ & 256.7 & 169.3 & 367.4 & 366.1 & 13.8 & 13.5 & 455.8 & 410.1 \\
\hline & $\mathrm{C} 03$ & 61.7 & 108.1 & 430.3 & 430.7 & 22.0 & 22.1 & 443.8 & 456.1 \\
\hline & $\mathrm{C} 04$ & 182.7 & 122.4 & 67.6 & 89.7 & 34.8 & 37.1 & 200.3 & 172.4 \\
\hline & $\mathrm{C} 05$ & 144.1 & 123.1 & 351.5 & 348.9 & 13.7 & 14.1 & 397.6 & 385.6 \\
\hline & mean & 172.5 & 150.0 & 300.8 & 304.6 & 19.2 & 19.5 & 373.4 & 360.2 \\
\hline \multirow{5}{*}{ IGSO } & $\mathrm{C} 06$ & 11.7 & 8.9 & 20.4 & 17.1 & 6.4 & 7.1 & 24.5 & 20.0 \\
\hline & $\mathrm{C} 07$ & 10.7 & 12.4 & 21.7 & 18.1 & 10.7 & 11.2 & 26.6 & 24.7 \\
\hline & $\mathrm{C} 08$ & 14.3 & 12.2 & 19.6 & 18.6 & 7.6 & 9.8 & 25.6 & 23.9 \\
\hline & $\mathrm{C} 09$ & 13.5 & 15.5 & 19.3 & 17.9 & 5.9 & 7.8 & 24.5 & 25.3 \\
\hline & C10 & 17.2 & 20.4 & 21.0 & 19.8 & 8.8 & 9.2 & 28.8 & 32.7 \\
\hline
\end{tabular}


Table 5. Cont

\begin{tabular}{|c|c|c|c|c|c|c|c|c|c|}
\hline \multirow{2}{*}{ Satellite Type } & \multirow{2}{*}{ PRN } & \multicolumn{2}{|c|}{ Along-Track } & \multicolumn{2}{|c|}{ Cross-Track } & \multicolumn{2}{|c|}{ Radial } & \multicolumn{2}{|c|}{$3 \mathrm{D}$} \\
\hline & & S1 & S2 & S1 & S2 & S1 & S2 & S1 & S2 \\
\hline \multirow{2}{*}{ IGSO } & C15 & 16.6 & 12.3 & 16.3 & 15.2 & 5.1 & 5.5 & 24.0 & 23.1 \\
\hline & mean & 14.0 & 13.6 & 19.7 & 17.8 & 7.4 & 8.4 & 25.7 & 25.0 \\
\hline \multirow{4}{*}{ MEO } & C11 & 10.2 & 8.1 & 5.9 & 5.5 & 3.9 & 3.1 & 12.4 & 9.9 \\
\hline & $\mathrm{C} 12$ & 10.8 & 8.5 & 6.2 & 5.9 & 4.2 & 3.7 & 13.2 & 11.2 \\
\hline & $\mathrm{C} 14$ & 8.3 & 8.5 & 9.9 & 9.2 & 3.8 & 4.4 & 13.7 & 11.8 \\
\hline & mean & 9.8 & 8.4 & 7.3 & 6.9 & 4.0 & 3.7 & 13.1 & 11.0 \\
\hline
\end{tabular}

\subsubsection{SLR Assessment}

The results of the SLR assessment are shown in Table 6. The accuracy of IGSO satellites in strategy 1 is significantly better than that in strategy 2, with the C08 and C10 satellites improving by $29.2 \%$ and $14.5 \%$, respectively. The accuracy of the MEO satellites in strategy 1 is $5.7 \%$ higher than that in strategy 2. A comparison of the aforementioned improvement of the overlapping arcs reveals that the SLR test results are in line with the trend of the overlapping arc precision improvement. For GEO satellites, the precision of the overlapped arcs in the radial direction is better than $2.3 \mathrm{~cm}$, but the SLR test results show that a sub-meter level error exists. This outcome is attributed to the even distribution of the ground stations for GEO satellites, through which the internal precision can reach a relatively high level. However, the accuracy is lower than that of IGSO and MEO satellites owing to the stationary orbit of the GEO satellites. We can thus infer that the distribution of ground stations significantly influences the orbit accuracy. Improving the accuracy of the GEO satellite orbit determination under certain tracking conditions of ground stations requires further study.

Table 6. SLR assessment between strategies 1 and 2 (unit: $\mathrm{cm}$ ).

\begin{tabular}{|c|c|c|c|c|c|c|c|c|}
\hline \multirow{2}{*}{ PRN } & \multirow[t]{2}{*}{ Result } & \multirow{2}{*}{$\begin{array}{c}\text { Normal } \\
\text { Points }\end{array}$} & \multicolumn{2}{|c|}{ MEAN } & \multicolumn{2}{|c|}{ STD } & \multicolumn{2}{|c|}{ RMS } \\
\hline & & & S1 & S2 & S1 & S2 & S1 & S2 \\
\hline & C01 & 69 & -63.7 & -63.1 & 17.0 & 17.7 & 65.9 & 65.6 \\
\hline & C08 & 20 & 1.0 & 0.4 & 1.4 & 2.4 & 1.7 & 2.4 \\
\hline & $\mathrm{C} 10$ & 33 & -0.3 & -3.1 & 5.3 & 5.4 & 5.3 & 6.2 \\
\hline & C11 & 65 & -1.8 & -1.4 & 2.8 & 3.2 & 3.3 & 3.5 \\
\hline
\end{tabular}

\subsubsection{Orbit Dilution of Precision Analysis}

Based on the positioning dilution of precision (PDOP) theory [32], the orbit dilution of precision (ODOP) is used to quantitatively analyze the distribution of ground stations to verify the influence of the CNCORS on the BeiDou POD [12]. Various error corrections are ignored to illustrate the ODOP computation process; thus, the following is the observation equation [33]:

$$
\rho_{k}=\left[\left(x_{k}^{j}-X_{i k}\right)^{2}+\left(y_{k}^{j}-Y_{i k}\right)^{2}+\left(z_{k}^{j}-Z_{i k}\right)^{2}\right]^{1 / 2}+\varepsilon_{k}
$$

In the equation, $\rho_{k}$ is the distance measurement; $t_{k}$ is the observation epoch; $\left(X_{i k}, Y_{i k}, Z_{i k}\right)$, $\left(x_{k}{ }^{j}, y_{k}{ }^{j}, z_{k}{ }^{j}\right)$ are the position vectors of satellite $\mathrm{j}$ and observation station $i$ in the epoch $k$, respectively; and $\varepsilon_{k}$ is the measurement error. The above equation is rewritten as the error equation and linearized as [34-36]:

$$
\Delta \rho_{k}=H_{k} \Delta X+\varepsilon_{k}
$$

where:

$$
H_{k}=\left[\begin{array}{lll}
\frac{x_{k}{ }^{j}-X_{i k}}{R_{i k}{ }^{j}} & \frac{y_{k}{ }^{j}-Y_{i k}}{R_{i k}{ }^{j}} & \frac{z_{k}{ }^{j}-Z_{i k}}{R_{i k}{ }^{j}}
\end{array}\right]=\frac{1}{R_{i k^{j}}{ }^{j}}\left[\begin{array}{lll}
\Delta x_{i k^{j}} & \Delta y_{i k}{ }^{j} & \Delta z_{i k^{j}}
\end{array}\right]
$$

According to Equation (2), the correction of the satellite position can be solved by using the least squares adjustment: 


$$
\Delta X=\left(H^{\mathrm{T}} H\right)^{-1} H^{\mathrm{T}} \Delta \rho_{k}
$$

The following is the orbit determination error of Equation (3) [32]:

$$
\begin{gathered}
\sigma_{r}=\left(\hat{\sigma}_{x}^{2}+\hat{\sigma}_{y}^{2}+\hat{\sigma}_{z}^{2}\right)^{\frac{1}{2}}=\left[\operatorname{tr}\left(H^{\mathrm{T}} H\right)^{-1}\right]^{\frac{1}{2}} \cdot \hat{\sigma}_{0} \\
O D O P=\left[\operatorname{tr}\left(H^{\mathrm{T}} H\right)^{-1}\right]^{\frac{1}{2}}
\end{gathered}
$$

In Equation (4), $\hat{\sigma}_{0}$ is the standard error of unit weight, and $t r$ is the trace of the matrix. ODOP is closely related to the spatial distribution of the ground stations. Usually, a smaller ODOP value and standard error of the unit weight yields a higher orbit determination accuracy. Given that the actual observations cannot reach the theoretical observations, using the theoretical satellite visible arc of the tracking station to compute the ODOP value is improper. Therefore, this study adopts the following method to compute the ODOP value: (1) The satellite position of each epoch is computed, such as $x_{k}{ }^{j}, y_{k}{ }^{j}, z_{k}{ }^{j}$; (2) Whether the station involved in the computation is determined according to the actual observation of each station in each epoch (i.e., the original observation file). If the satellite is observed in a certain epoch, then the station is included in the computation of this epoch; if a satellite is observed by fewer than four stations, then the ODOP value of this epoch is discarded; (3) After obtaining the ODOP value for each satellite in each epoch, the average ODOP values of the MEO, GEO, and IGSO satellites are computed.

The ODOP values for different strategies are computed, and the results are shown in Table 7. The results show that all ODOP values of strategy 1 are smaller than those of strategy 2 , and that the respective average ODOP values of the GEO, IGSO, and MEO satellites are $14.3 \%, 14.5 \%$, and $5.5 \%$ smaller. Therefore, the CNCORS strongly influence the geometry structure of BeiDou GEO and IGSO satellite orbit determination and only mildly influence the MEO satellites. The results of ODOP improvements match the improvements in the overlapping arc precision and SLR assessment accuracy of the BeiDou POD. In addition, the ODOP values of the GEO and IGSO satellites are improved to almost the same extent, but the accuracy improvement of IGSO satellite orbit determination was significantly higher than that of the GEO satellites, because IGSO satellites constantly move in the Asia-Pacific region. Such movement results in more ground tracking stations within the satellites' coverage, longer observation periods, more redundant observations, and, therefore, a higher orbit determination accuracy. However, GEO satellites are stationary relative to the Earth, and the relative observation geometry between the ground stations and a satellite in GEO is poorer. The accuracy of orbit determination is also low in itself; thus, the improvement of accuracy of orbit determination is

\begin{tabular}{|c|c|c|c|c|c|c|c|c|c|c|c|c|c|c|}
\hline $\begin{array}{ll} & \text { PRN } \\
\text { Strategies } & \end{array}$ & $\mathrm{C} 01$ & $\mathrm{C} 02$ & $\mathrm{C} 03$ & $\mathrm{CO4}$ & $\mathrm{C} 05$ & $\mathrm{C} 06$ & $\mathrm{C} 07$ & $\mathrm{C} 08$ & $\mathrm{C} 09$ & C10 & C15 & C11 & $\mathrm{C} 12$ & C14 \\
\hline $\mathrm{S} 1 / \mathrm{S} 3$ & 51.5 & 44.7 & 38.4 & 53.7 & 45.2 & 38.0 & 37.8 & 39.5 & 40.2 & 40.6 & 42.1 & 25.2 & 26.8 & 28.1 \\
\hline $\mathrm{S} 2 / \mathrm{S} 4$ & 65.2 & 51.3 & 44.8 & 60.0 & 51.3 & 45.0 & 44.9 & 46.4 & 46.4 & 47.2 & 48.6 & 26.9 & 28.1 & 29.8 \\
\hline
\end{tabular}
lower than that of IGSO satellites.

Table 7. ODOP comparison of different strategies.

\subsection{Impact of CNCORS on BDS Single-System POD}

Strategies 3 and 4 are compared to verify the contribution of CNCORS to the BeiDou single-system POD.

\subsubsection{Overlapping Arcs Precision}

Table 8 and Figure 3 show that the overlapping arcs precision from Strategy 3,which is based on the CNCORS and MGEX stations, has 3DRMS of 19.0, 7.6, and $11.0 \mathrm{~cm}$ for the GEO, IGSO, and MEO 
satellites, respectively. Among them, IGSO satellites have the highest precision, because more stations exist within the operation area of IGSO satellites, with stations in China, Southeast Asia, Australia, and the surrounding areas. These ground stations are evenly distributed in this region and able to provide a longer observation period for IGSO satellites. Compared with strategy 4 , the average 3D precision of the GEO, IGSO, and MEO satellites of strategy 3 is improved by $15.6 \%, 29.6 \%$, and $5.2 \%$, respectively. IGSO satellites experience the most improvement, which is consistent with the results of the joint orbit determination in the previous section.

Table 8. Comparison of overlapping arcs precision between strategies 3 and 4 (unit: $\mathrm{cm}$ ).

\begin{tabular}{|c|c|c|c|c|c|c|c|c|c|}
\hline \multirow{2}{*}{ Satellite Type } & \multirow{2}{*}{ PRN } & \multicolumn{2}{|c|}{ Along-Track } & \multicolumn{2}{|c|}{ Cross-Track } & \multicolumn{2}{|c|}{ Radial } & \multicolumn{2}{|c|}{$3 \mathrm{D}$} \\
\hline & & S3 & S4 & S3 & S4 & S3 & S4 & S3 & S4 \\
\hline \multirow{6}{*}{ GEO } & C01 & 20.5 & 24.8 & 2.7 & 3.3 & 2.8 & 3.5 & 21.2 & 25.3 \\
\hline & $\mathrm{C} 02$ & 18.7 & 18.9 & 2.7 & 3.3 & 3.1 & 4.2 & 19.1 & 19.7 \\
\hline & $\mathrm{C} 03$ & 14.5 & 20.4 & 2.7 & 3.5 & 2.1 & 2.5 & 15.1 & 21.3 \\
\hline & $\mathrm{C} 04$ & 19.0 & 19.5 & 3.5 & 4.9 & 4.1 & 4.8 & 20.0 & 21.1 \\
\hline & $\mathrm{C} 05$ & 17.9 & 24.0 & 4.5 & 5.1 & 4.0 & 4.5 & 19.6 & 25.2 \\
\hline & mean & 18.1 & 21.5 & 3.2 & 4.0 & 3.2 & 3.9 & 19.0 & 22.5 \\
\hline \multirow{7}{*}{ IGSO } & C06 & 3.9 & 5.2 & 5.4 & 6.4 & 3.1 & 3.8 & 7.7 & 9.8 \\
\hline & C07 & 4.8 & 6.8 & 3.8 & 6.2 & 4.5 & 5.2 & 7.9 & 11.1 \\
\hline & C08 & 4.6 & 6.0 & 4.5 & 4.9 & 3.7 & 4.8 & 7.6 & 9.4 \\
\hline & C09 & 4.3 & 5.9 & 5.1 & 6.9 & 3.3 & 4.5 & 7.7 & 10.6 \\
\hline & C10 & 4.8 & 9.8 & 4.0 & 7.2 & 3.3 & 4.2 & 7.3 & 13.8 \\
\hline & $\mathrm{C} 15$ & 5.1 & 7.0 & 4.3 & 5.8 & 3.1 & 3.8 & 7.6 & 10.3 \\
\hline & mean & 4.6 & 6.8 & 4.5 & 6.2 & 3.5 & 4.4 & 7.6 & 10.8 \\
\hline \multirow{4}{*}{ MEO } & C11 & 10.0 & 9.8 & 4.3 & 4.6 & 3.0 & 3.2 & 11.4 & 11.5 \\
\hline & C12 & 10.1 & 10.0 & 3.7 & 4.4 & 3.4 & 3.5 & 11.5 & 12.4 \\
\hline & C14 & 8.2 & 8.8 & 4.3 & 5.1 & 2.8 & 2.7 & 10.1 & 10.9 \\
\hline & mean & 9.4 & 9.5 & 4.1 & 4.7 & 3.1 & 3.1 & 11.0 & 11.6 \\
\hline
\end{tabular}

For Strategy 3, the average radial RMS of all three types of satellites is better than $3.5 \mathrm{~cm}$, and the cross-track RMS is better than $4.5 \mathrm{~cm}$. For the along-track direction, the RMS is $4.6 \mathrm{~cm}$ for IGSO satellites, $18.1 \mathrm{~cm}$ for GEO satellites, and $9.4 \mathrm{~cm}$ for MEO satellites. Therefore, the orbit precision from the BDS single-system method can be relatively high in cases with more evenly distributed ground tracking stations. GEO satellites have the worst accuracy in the along-track direction because their stationary characteristics are related to large orbit errors, and the along-track orbit component of GEO satellites is strongly correlated with other parameters, such as ambiguities.

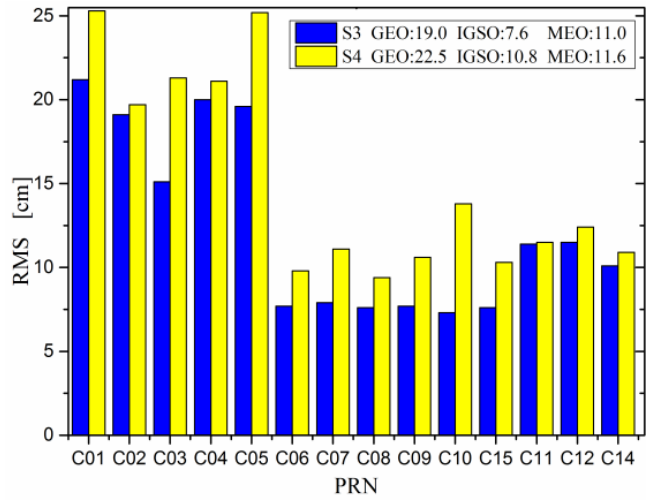

(a)

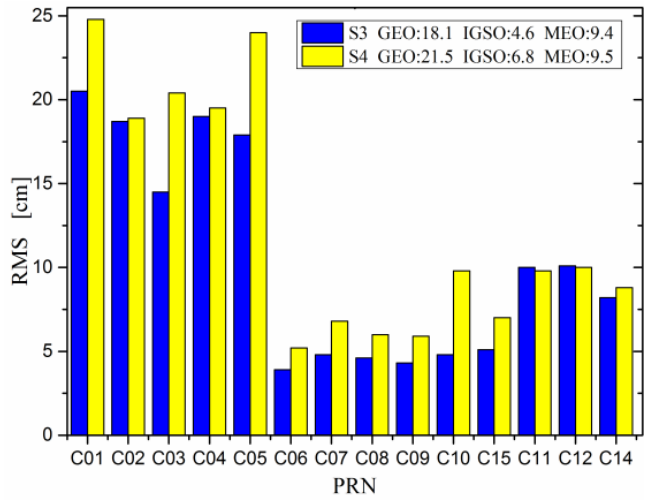

(b)

Figure 3. Cont. 


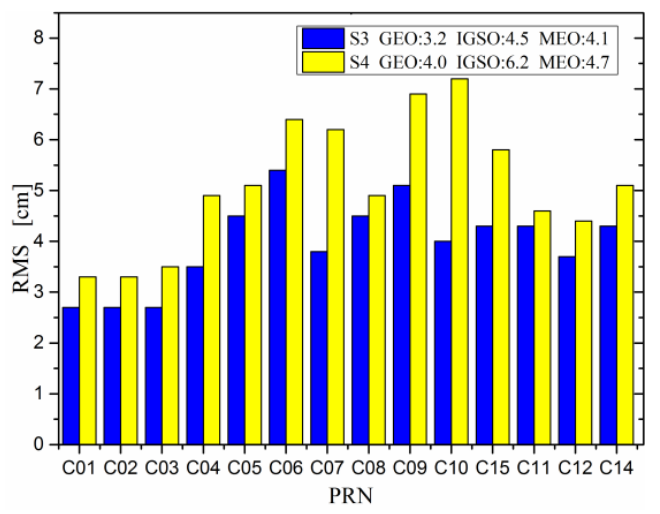

(c)

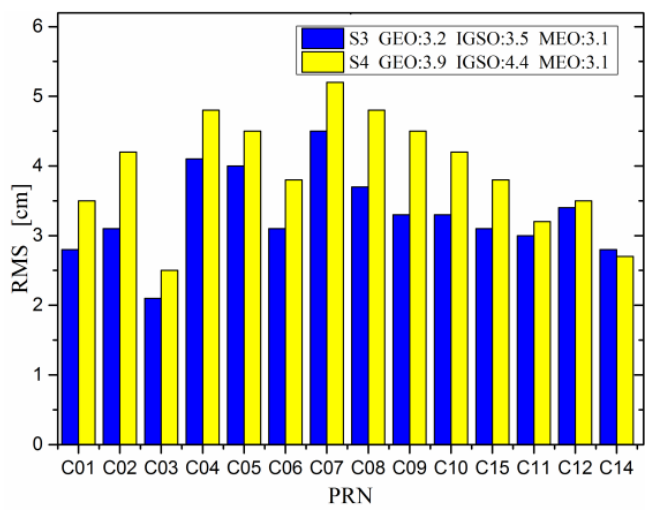

(d)

Figure 3. Comparison of overlapping arcs precision between strategies 3 and 4. (a) 3DRMS; (b) Along-track RMS; (c) Cross-track RMS; (d) Radial RMS.

\subsubsection{Comparisons with GBM Orbit}

Strategies 3 and 4 are compared with the GBM BeiDou orbit products, and the results are shown in Figure 4 and Table 9. The table shows that the GEO and MEO satellites exhibit a slight difference when compared to the GBM orbit and present no obvious features. For IGSO satellites, the difference between the orbit solution from strategy 3 and the GBM orbit is smaller than that between the solution from strategy 4 and the GBM orbit, because under the single-system BeiDou orbit determination mode, the accuracy of the IGSO satellite orbit determination in strategy 3 is considerably better than that in strategy 4 and undergoes the most significant improvement. Such an improvement results in a larger difference between the orbit solution from strategy 4 and the GBM orbit in terms of IGSO satellite accuracy.
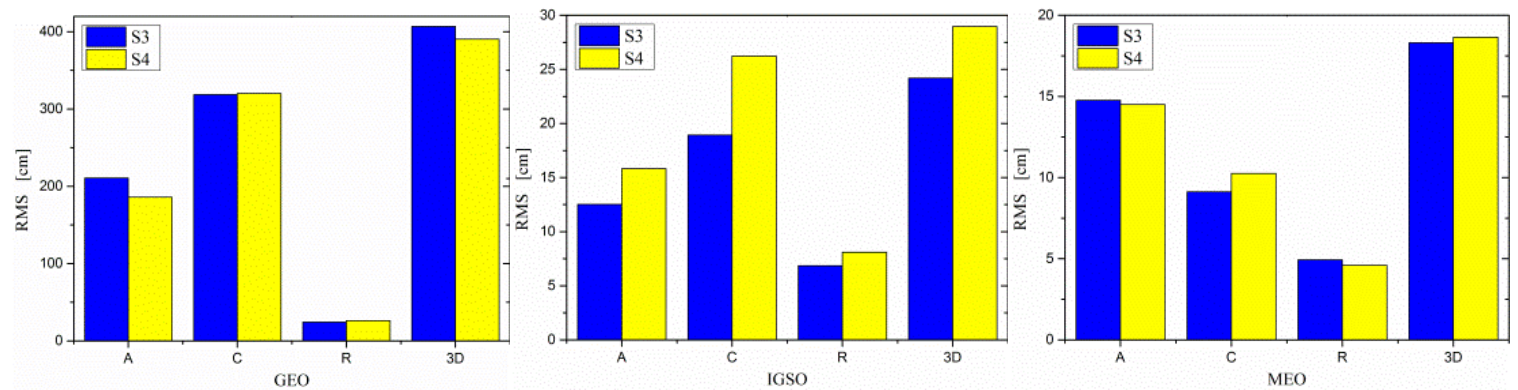

Figure 4. Comparison with GBM orbit from strategies 3 and 4.

Table 9. Comparison with GBM orbit from strategies 3 and 4 (unit:cm).

\begin{tabular}{|c|c|c|c|c|c|c|c|c|}
\hline \multirow{2}{*}{ Strategy } & \multicolumn{2}{|c|}{ Along-Track } & \multicolumn{2}{|c|}{ Cross-Track } & \multicolumn{2}{|c|}{ Radial } & \multicolumn{2}{|c|}{$3 \mathrm{D}$} \\
\hline & S3 & $\mathrm{S} 4$ & S3 & $\mathrm{S} 4$ & S3 & S4 & S3 & $\mathrm{S} 4$ \\
\hline $\mathrm{C} 01$ & 214.2 & 228.7 & 288.4 & 290.6 & 13.1 & 13.7 & 368.6 & 380.4 \\
\hline $\mathrm{C} 02$ & 355.7 & 269.8 & 386.5 & 391.8 & 16.1 & 15.6 & 551.3 & 483.3 \\
\hline $\mathrm{C} 03$ & 149.9 & 152.6 & 442.4 & 455.2 & 38.4 & 47.2 & 477.8 & 492.6 \\
\hline $\mathrm{C} 04$ & 190.2 & 152.6 & 112.9 & 120.9 & 37.8 & 38.1 & 228.9 & 194.7 \\
\hline C05 & 143.1 & 125.8 & 363.0 & 341.3 & 15.8 & 16.6 & 407.8 & 401.1 \\
\hline Mean & 210.6 & 185.9 & 318.6 & 320.0 & 24.2 & 26.2 & 406.9 & 390.4 \\
\hline
\end{tabular}


Table 9. Cont.

\begin{tabular}{|c|c|c|c|c|c|c|c|c|}
\hline \multirow{2}{*}{ Strategy } & \multicolumn{2}{|c|}{ Along-Track } & \multicolumn{2}{|c|}{ Cross-Track } & \multicolumn{2}{|c|}{ Radial } & \multicolumn{2}{|c|}{$3 \mathrm{D}$} \\
\hline & S3 & S4 & S3 & S4 & S3 & S4 & S3 & S4 \\
\hline C06 & 10.3 & 12.1 & 20.4 & 44.1 & 6.5 & 7.2 & 24.0 & 23.3 \\
\hline $\mathrm{C} 07$ & 10.2 & 13.1 & 18.8 & 22.2 & 9.5 & 12.2 & 23.5 & 29.4 \\
\hline C08 & 12.8 & 10.0 & 19.6 & 24.7 & 6.3 & 7.2 & 24.9 & 27.5 \\
\hline C09 & 11.9 & 17.2 & 21.0 & 22.0 & 5.6 & 7.6 & 25.0 & 29.3 \\
\hline C10 & 14.0 & 27.9 & 18.4 & 24.8 & 7.7 & 8.6 & 24.7 & 39.0 \\
\hline C15 & 15.9 & 14.6 & 15.4 & 19.6 & 5.6 & 5.9 & 23.1 & 25.4 \\
\hline Mean & 12.5 & 15.8 & 18.9 & 26.2 & 6.9 & 8.1 & 24.2 & 29.0 \\
\hline C11 & 14.5 & 13.1 & 7.9 & 9.7 & 4.9 & 4.2 & 17.3 & 17.1 \\
\hline C12 & 16.1 & 15.6 & 8.4 & 10.6 & 5.2 & 4.8 & 19.0 & 19.6 \\
\hline C14 & 13.7 & 14.8 & 11.2 & 10.5 & 4.7 & 4.7 & 18.6 & 19.2 \\
\hline Mean & 14.8 & 14.5 & 9.1 & 10.3 & 4.9 & 4.6 & 18.3 & 18.6 \\
\hline
\end{tabular}

\subsubsection{SLR Assessment}

The SLR test results of strategies 3 and 4 are shown in Table 10. The table shows that the BeiDou single-system and BDS/GPS joint orbit determinations present consistent features: the CNCORS have the greatest impact on IGSO satellites, followed by MEO satellites, and the least impact on GEO satellites.

Table 10. SLR assessment of strategies 3 and 4 (unit: $\mathrm{cm}$ ).

\begin{tabular}{|c|c|c|c|c|c|c|c|}
\hline \multirow{2}{*}{ PRN } & \multirow{2}{*}{$\begin{array}{c}\text { Normal } \\
\text { Points }\end{array}$} & \multicolumn{2}{|c|}{ MEAN } & \multicolumn{2}{|c|}{ STD } & \multicolumn{2}{|c|}{ RMS } \\
\hline & & S3 & S4 & S3 & S4 & S3 & S4 \\
\hline C01 & 69 & -65.1 & -64.5 & 18.3 & 17.7 & 67.6 & 66.9 \\
\hline $\mathrm{C} 08$ & 20 & 0.9 & 1.4 & 4.6 & 6.0 & 4.6 & 6.1 \\
\hline C10 & 33 & -3.1 & -9.4 & 13.2 & 13.9 & 13.4 & 16.6 \\
\hline C11 & 65 & -0.7 & 1.0 & 4.7 & 5.5 & 4.8 & 5.6 \\
\hline
\end{tabular}

\subsection{Comparison between BDS Single-System and Joint POD}

To compare the accuracy of BDS single-system orbit determination and BDS/GPS joint orbit determination, strategies 1 and 3 are compared.

\subsubsection{Overlapping Arcs Precision}

Table 11 and Figure 5 show that in terms of the average RMS of GEO, IGSO, and MEO satellites, the precision of strategy 1 is much better than that of strategy 3. A comparison of the 3D precision of strategies 1 and 3 reveals that the accuracy of GEO satellites improves by $9.5 \%$, whereas the accuracy of the IGSO and MEO satellites improves by $35.5 \%$ and $49.1 \%$, respectively.

Table 11. Comparison of overlapping arcs precision between strategies 1 and 3 (unit: $\mathrm{cm}$ ).

\begin{tabular}{|c|c|c|c|c|c|c|c|c|}
\hline \multirow{2}{*}{$\begin{array}{ll}\text { Type } & \text { Precision } \\
\end{array}$} & \multicolumn{2}{|c|}{ Along-Track } & \multicolumn{2}{|c|}{ Cross-Track } & \multicolumn{2}{|c|}{ Radial } & \multicolumn{2}{|c|}{ 3D } \\
\hline & S1 & S3 & S1 & S3 & S1 & S3 & S1 & S3 \\
\hline GEO & 16.6 & 18.1 & 1.7 & 3.2 & 1.5 & 3.2 & 17.2 & 19.0 \\
\hline IGSO & 3.1 & 4.6 & 2.9 & 4.5 & 1.9 & 3.5 & 4.9 & 7.6 \\
\hline MEO & 4.0 & 9.4 & 2.5 & 4.1 & 1.5 & 3.1 & 5.6 & 11.0 \\
\hline
\end{tabular}

The results show that the BDS/GPS joint orbit determination has the greatest impact on MEO satellites, followed by IGSO satellites, which can be attributed to the global coverage of MEO satellites. In the joint orbit determination, the GPS data are used to determine accurate station coordinates, 
receiver clock error, and other parameters. Thus, the precision improvement of MEO satellites is higher than that of the other types of satellites. GEO satellites are the least affected. Figure 5 shows that strategy 3 is superior to strategy 1 in terms of the along-track precision of the C01, C02, and C04 satellite. The stationary orbit of GEO satellites results in a small difference between BeiDou and GPS data for a determination of the parameters, resulting in a lower impact of the joint orbit determination on GEO satellites.

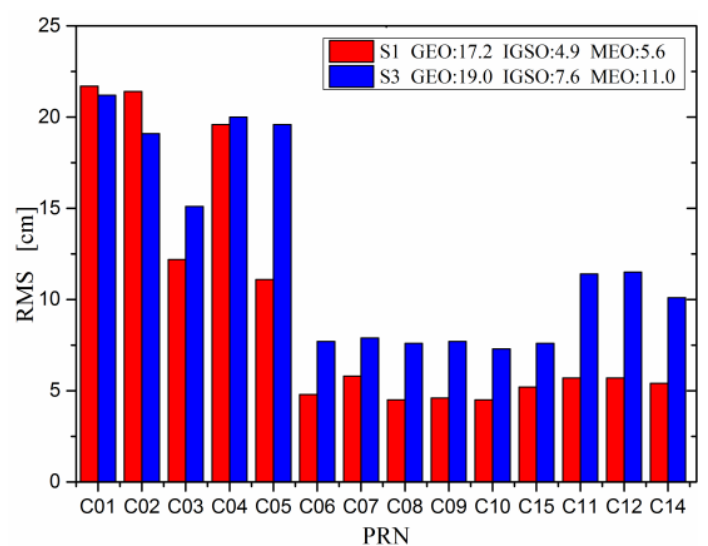

(a)

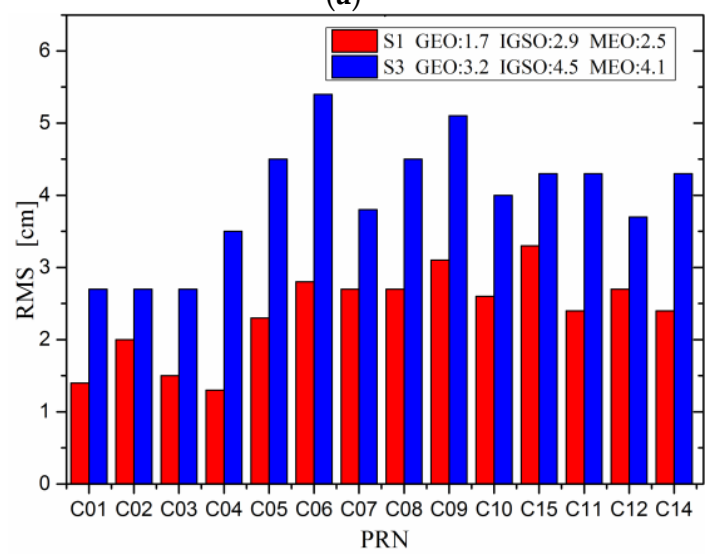

(c)

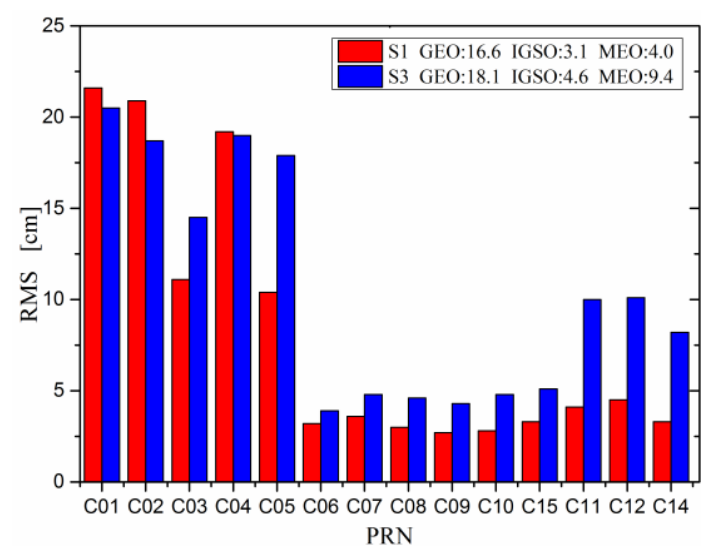

(b)

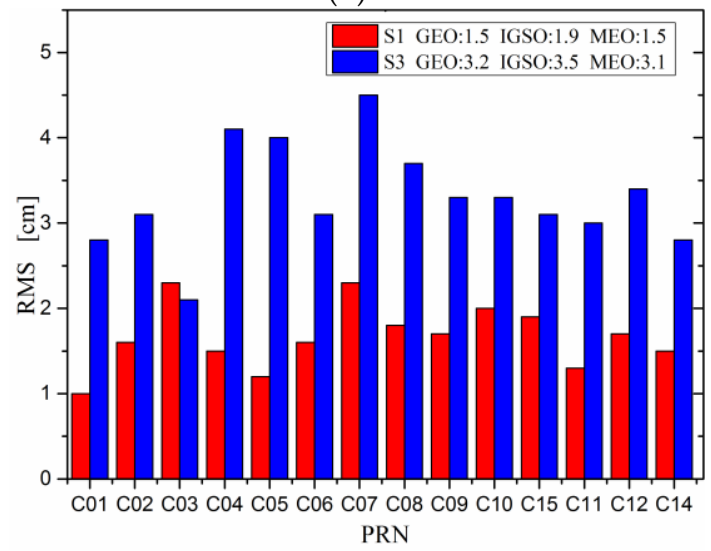

(d)

Figure 5. Comparison of overlapping arcs precision between strategies 1 and 3. (a) 3DRMS; (b) Along-track RMS; (c) Cross-track RMS; (d) Radial RMS.

On average, the precision of strategy 1 is $26.2 \%$ higher in the along-track direction, $39.8 \%$ higher in the cross-track direction, and 50\% higher in the radial direction than strategy 3 . However, the statistics involve GEO satellites. To better illustrate the influence of joint orbit determination on each direction, we only account for IGSO and MEO satellites. The results show that the along, cross-track, and radial-track directions were improved by $49.3 \%, 37.2 \%$, and $48.5 \%$, respectively. This result indicates that the joint orbit determination has the greatest impact on the radial direction, followed by the along-track direction, and has the least impact on the cross-track direction, excluding GEO satellites.

\subsubsection{Comparison with GBM Orbit}

Strategies 1 (Table 5) and 3 (Table 9) are compared with the GBM orbit products, and the results are shown in Figure 6. The figure shows that the results compared with the GBM orbit are different from the results of the overlapping arcs precision. Among them, for GEO and MEO satellites, the difference between strategy 1 and GBM is less than that of strategy 3. On the contrary, for IGSO satellites, the difference between strategy 1 and the GBM orbit is larger than that of strategy 3. 

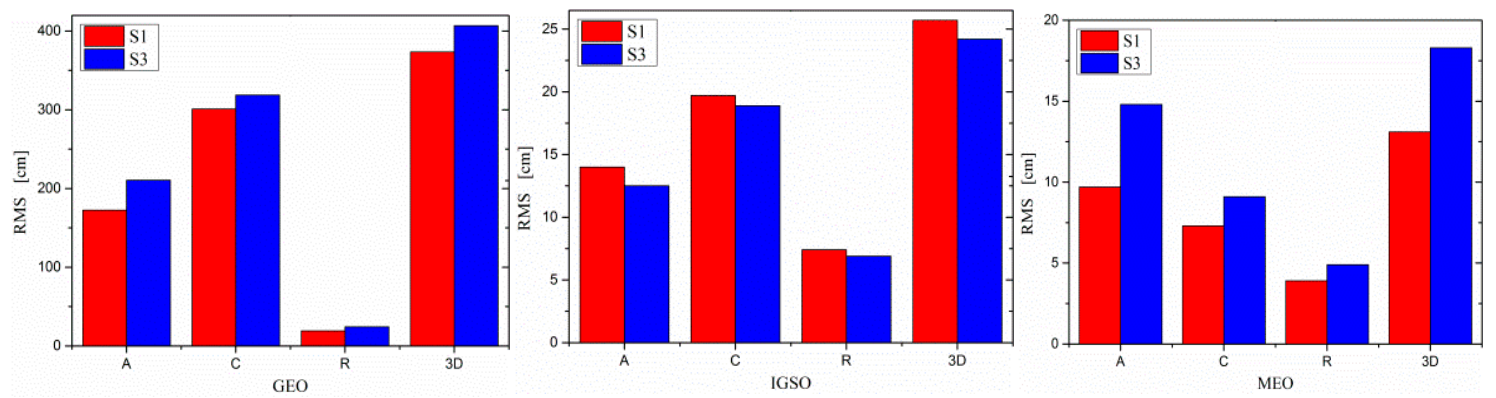

Figure 6. Comparison with the GBM orbit from strategies 1 and 3 (unit: $\mathrm{cm}$ ).

\subsubsection{SLR Assessment}

The SLR test results of strategies 1 and 3 are compared, and the results are shown in Tables 6 and 10. The tables show that the C01 satellite, as described in the previous section, has a systematic error. Strategy 1 is significantly better than strategy 3 in the case of the IGSO and MEO satellites. The accuracy of C08 and C10 was improved by $63.0 \%$ and $60.4 \%$, respectively, and the C11 satellite was improved by $31.3 \%$. These results are consistent with the radial precision of the overlapping arcs.

\section{Discussion}

In this study, the BDS/GPS observation data collected by IGS/MGEX and the CNCORS are used to determine the precision orbit of the BeiDou satellites. The results show that a high-precision BeiDou satellite orbit can be obtained when the stations are well distributed. In the four strategies of this paper, the BDS/GPS joint orbit determination based on observation data from 124 stations yields the highest accuracy. The 3D overlapping arcs precision of the GEO, IGSO, and MEO satellites is $17.2,4.9$, and $5.6 \mathrm{~cm}$, respectively, and the radial precisions are all better than $2.3 \mathrm{~cm}$. Our results are quite encouraging when compared to those reported by previous studies. In the latest literature, publication [3] achieved a radial overlap precision at the $0.1 \mathrm{~m}$ level for both BeiDou GEO and IGSO satellites. The 3D overlap precision of the GEO, IGSO, and MEO satellites in literature [8] reached 155, 33 , and $28 \mathrm{~cm}$, respectively, and the radial overlapping arcs precision was basically better than $10 \mathrm{~cm}$. The most precise orbit of IGSO and MEO satellites obtained in literature [12] has an accuracy of 13.2 and $11.9 \mathrm{~cm}$, respectively.

Consistent with previous studies [2,6,10-12], GEO satellites have the worst precision among the three types of satellites. The main reason for this phenomenon is the much smaller changes of the observation geometry of the GEO satellites compared to the IGSO and MEO satellites. As a result, strong correlations occur among the orbital elements, solar radiation pressure parameters, ambiguities, and ISBs, which resulted in large errors in the along-track direction [6]. However, the precision of the GEO satellites in the cross-track direction is better than that of the IGSO and MEO satellites. Further studies are needed to explain this result.

We analyzed the beta angles (the elevation angles of the Sun above the satellite orbital planes) of BeiDou satellites in the considered period. The results show that the beta angels of all the GEO satellites are 17-19 degrees. For all the MEO satellites, the absolute value of beta angles is greater than 28 degrees. For IGSO satellites, the absolute values of the beta angle of C06, C08, C09, C15 are greater than 22 degrees. The beta angle of IGSO C07 ranges from -1.9 to 10.4 degrees, and that of IGSO C10 ranges from -1.5 to 10.9 degrees. It is noted that the absolute value of the beta angle of $\mathrm{C} 07$ is less than 4 degrees most of the time, so that the orbit precision is relatively low [37]. Take the results of the strategies 1 and 2 as an example, the 3DRMS values of $\mathrm{C} 07$ are $18.4 \%$ and $13 \%$ higher than the average values of IGSO, respectively.

The lack of ground stations is one of the reasons for the low precision of the BeiDou orbit in previous studies, especially in the current service regions such as in China. Literature $[9,12]$ show that the addition of ground stations in proper areas significantly improves the orbit determination accuracy 
of BeiDou satellites. This paper found that the addition of 24 stations in China greatly improved the accuracy of the BeiDou orbit determination, especially for the IGSO satellites. For the BeiDou/GPS joint orbit determination method and the single-system BeiDou orbit determination method, the precision of IGSO satellites is improved by $36.4 \%$ and $29.6 \%$, respectively. BDS single-system orbit determination can achieve an acceptable accuracy, and the 3D overlapping arc precision of the GEO, IGSO, and MEO satellites is 19.0, 7.6, and $11.0 \mathrm{~cm}$, respectively. However, the accuracy of BDS/GPS joint orbit determination is higher than that of the BeiDou single-system orbit determination, indicating that GPS can helps to strengthen the parameter estimation, such as the tropospheric delay and receiver clock error.

The difference between BDS/GPS joint orbit determination (strategy 1) and BeiDou single-system orbit determination (strategy 3) was further analyzed. In contrast with other assessment results, for IGSO satellites, the difference between the orbit solution from strategy 1 and the GBM orbit is larger than that of the orbit solution from strategy 3. The reason for this is that the GBM orbit adopts the BDS/GPS joint orbit determination method, which is identical to strategy 1 , and the difference is small. The reason for the different results of the IGSO satellites stems from the addition of the CNCORS in the orbit determination and the improvement of IGSO orbits. Therefore, the difference between strategy 1 and the GBM orbit is large, and the accuracy of strategy 3 is slightly worse than that of strategy 1 , but less different from the GBM orbit. In other words, the GBM orbit is different from the orbit in strategies 3 and 1 for different reasons, which are the addition of the CNCORS and the accuracy of some parameters of BDS/GPS joint orbit determination, respectively.

Improvement of the BeiDou system is still required in terms of refining the satellite solar radiation model, the phase center correction of satellite antenna, the evenness of ground station distribution, and other aspects. The recent progress in the field of multi-GNSS precise positioning, including BDS-based precise positioning, inter-system biases, etc., should also be considered [38-42].

\section{Conclusions}

The data used in this study are the BDS/GPS observation data collected by IGS/MGEX and the CNCORS, from July to August in 2016. The BDS/GPS joint and BDS single-system orbit determinations are used for orbit determination. The accuracy evaluation is conducted by means of overlapping arcs precision, a comparison with the GBM orbit, and an SLR assessment. The ODOP values of the different distribution strategies are analyzed. In this paper, the influence of the CNCORS on the accuracy of BeiDou orbit determination is comprehensively analyzed, and the differences between the solutions derived from different orbit determination methods are tested and compared. This paper obtained some useful conclusions through the comprehensive analysis of BeiDou orbit determination, and the calculation results and analysis conclusions can provide a reference for BeiDou precise orbit determination in the future. The following conclusions can be drawn from the numerical comparison and analysis:

(1) The BDS/GPS joint orbit determinations based on observation data from the 124 stations worldwide yield the highest BeiDou orbit determination accuracies in this paper. The radial overlapping arc precision is better than $2.3 \mathrm{~cm}$ for all three types of BeiDou satellites. The results of satellite laser ranging (SLR) residuals show that the RMS of the IGSO and MEO satellites is better than $5 \mathrm{~cm}$.

(2) The addition of the CNCORS greatly improves the accuracy of the BeiDou orbit determination. The analysis of the overlapping arc precision and the SLR assessment results show that the CNCORS most strongly influence the IGSO satellites, less strongly influence the GEO satellites, and have the least influence on MEO satellites.

(3) By comparing the BDS single-system orbit determination and the BDS/GPS joint orbit determination, we found that the joint orbit determination has the biggest influence on MEO satellites. Among the comparisons of the three orbital directions, the radial direction is improved the most by joint orbit determination, followed by the along-track direction, and the cross-track direction is improved the least. 
(4) The ODOP value of the satellite and the ground tracking stations can be adopted to examine the geometrical configuration. The ODOP value of the different station distribution strategy is generally consistent with the accuracy of the orbit determination, i.e., a smaller ODOP value yields a higher orbit accuracy.

Acknowledgments: We would like to acknowledge the efforts of the IGS MGEX campaign in providing the multi-GNSS data. We would like to acknowledge the ILRS for SLR observations. This work is supported by the National Natural Science Foundation of China (No. 41374034) and the National Key Research and Development Program of China (Grant No. 2016YFB0501802 and No. 2017YFF0212005).

Author Contributions: M.C. and J.G. conceptualized the initial idea and experiment design; M.C. and Y.L. wrote the main manuscript text; and the other authors helped with the writing of the text.

Conflicts of Interest: The authors declare no competing financial interests.

\section{References}

1. Yang, Y.X. Progress, contribution and challenges of Compass/Beidou satellite navigation system. Acta Geod. Cartogr. Sin. 2010, 39, 1-6.

2. Ge, M.R.; Zhang, H.P.; Jia, X.L.; Song, S.L.; Wickert, J. What is achievable with the current compass constellation. GPS World 2012, 11, 29-34.

3. Shi, C.; Zhao, Q.L.; Li, M.; Tang, W.M.; Hu, Z.G.; Lou, Y.D.; Zhang, H.P.; Niu, X.J.; Liu, J.N. Precise orbit determination of Beidou Satellites with precise positioning. Sci. China Earth Sci. 2012, 55, 1079-1086. [CrossRef]

4. Montenbruck, O.; Hauschild, A.; Steigenberger, P.; Hugentobler, U.; Teunissen, P.; Nakamura, S. Initial assessment of the COMPASS/BeiDou-2 regional navigation satellite system. GPS Solut. 2013, 17, 211-222. [CrossRef]

5. Zhao, Q.; Guo, J.; Li, M.; Liu, J.N. Initial results of precise orbit and clock determination for COMPASS navigation satellite system. J. Geod. 2013, 87, 475-486. [CrossRef]

6. Steigenberger, P.; Hugentobler, U.; Hauschild, A.; Montenbruck, O. Orbit and clock analysis of Compass GEO and IGSO satellites. J. Geod. 2013, 87, 515-525. [CrossRef]

7. Zhou, S.S.; Hu, X.G.; Zhou, J.H.; Chen, J.P.; Gong, X.; Tang, C.; Wu, B.; Liu, L.; Guo, R.; He, F.; et al. Accuracy analyses of precise orbit determination and timing for COMPASS/Beidou-2 4GEO/5IGSO/4MEO constellation. Lect. Notes Electr. Eng. 2013, 245, 89-102. [CrossRef]

8. Liu, Y.; Lou, Y.; Shi, C.; Zheng, F.; Yin, Q. BeiDou regional navigation system network solution and precision analysis. Lect. Notes Electr. Eng. 2013, 245, 173-186. [CrossRef]

9. He, L.N.; Ge, M.R.; Wang, J.X.; Wickert, J.; Schuh, H. Experimental study on the precise orbit determination of the BeiDou navigation satellite system. Sensors 2013, 13, 2911-2928. [CrossRef] [PubMed]

10. Lou, Y.D.; Liu, Y.; Shi, C.; Yao, X.G.; Zheng, F. Precise orbit determination of BeiDou constellation based on BETS and MGEX network. Sci. Rep. 2014, 4, 4692. [CrossRef] [PubMed]

11. Lou, Y.D.; Liu, Y.; Shi, C.; Wang, B.; Yao, X.G.; Zheng, F. Precise orbit determination of BeiDou constellation: Method comparison. GPS Solut. 2016, 20, 259-268. [CrossRef]

12. Zhang, R.; Zhang, Q.; Huang, G.; Wang, L.; Qu, W. Impact of tracking station distribution structure on BeiDou satellite orbit determination. Adv. Space Res. 2015, 56, 2177-2187. [CrossRef]

13. Deng, Z.; Fritsche, M.; Uhlemann, M.; Wickert, J.; Schuh, H. Reprocessing of GFZ Multi-GNSS product GBM. In Proceedings of the IGS Workshop, Sydney, Australia, 8-12 February 2016.

14. Liu, J.H.; Gu, D.F.; Ju, B.; Shen, Z.; Lai, Y.W.; Yi, D.Y. A new empirical solar radiation pressure model for BeiDou GEO satellites. Adv. Space Res. 2016, 57, 234-244. [CrossRef]

15. Tan, B.F.; Yuan, Y.B.; Zhang, B.C.; Hsu, H.Z.; Ou, J.K. A new analytical solar radiation pressure model for current BeiDou satellites: IGGBSPM. Sci. Rep. 2016, 6, 32967. [CrossRef] [PubMed]

16. Guo, J.; Chen, G.; Zhao, Q.L.; Liu, J.N.; Liu, X.L. Comparison of solar radiation pressure models for BDS IGSO and MEO satellites with emphasis on improving orbit quality. GPS Solut. 2017, 21, 511-522. [CrossRef]

17. Capuano, V.; Shehaj, E.; Blunt, P.; Botteron, C.; Farine, P.-A. High accuracy GNSS based navigation in GEO. Acta Astronaut. 2017, 136, 332-341. [CrossRef] 
18. Wang, W.; Chen, G.C.; Guo, S.R.; Song, X.Y.; Zhao, Q.L. A study on the Beidou IGSO/MEO satellite orbit determination and prediction of the different yaw control mode. Lect. Notes Electr. Eng. 2013, 245, 31-40. [CrossRef]

19. Guo, J.; Zhao, Q.L.; Geng, T.; Su, X.; Liu, J.N. Precise orbit determination for COMPASS IGSO satellites during yaw maneuvers. Lect. Notes Electr. Eng. 2013, 245, 41-53. [CrossRef]

20. Dai, X.L.; Ge, M.R.; Lou, Y.D.; Shi, C.; Wickert, J.; Schuh, H. Estimating the yaw-attitude of BDS IGSO and MEO satellites. J. Geod. 2015, 89, 1005-1018. [CrossRef]

21. Fan, L.; Jiang, C.; Hu, M. Ground track maintenance for BeiDou IGSO satellites subject to tesseral resonances and the luni-solar perturbations. Adv. Space Res. 2017, 59, 753-761. [CrossRef]

22. Dilssner, F.; Springer, T.; Schönemann, E.; Enderle, W. Estimation of satellite antenna phase center corrections for BeiDou. In Proceedings of the IGS Workshop, Pasadena, CA, USA, 23-27 June 2014.

23. Montenbruck, O.; Steigenberger, P.; Prange, L.; Deng, Z.G.; Zhao, Q.L.; Perosanz, F.; Romero, I.; Noll, C.; Stürze, A.; Weber, G.; et al. The Multi-GNSS Experiment (MGEX) of the International GNSS Service (IGS)-Achievements, prospects and challenges. Adv. Space Res. 2017, 59, 1671-1697. [CrossRef]

24. Chen, J.Y.; Zhang, P.; Wu, J.L.; Zhang, Q.D. On Chinese national continuous operating reference station system of GNSS. Acta Geod. Cartog. Sin. 2007, 36, 366-369.

25. Liu, J.N.; Ge, M.R. PANDA software and its preliminary result of positioning and orbit determination. Wuhan Univ. J. Nat. Sci. 2003, 8, 603-609. [CrossRef]

26. Boehm, J.; Heinkelmann, R.; Schuh, H. Short note: A global model of pressure and temperature for geodetic applications. J. Geod. 2007, 81, 679-683. [CrossRef]

27. Boehm, J.; Niell, A.; Tregoning, P.; Schuh, H. Global Mapping Function (GMF): A new empirical mapping function based on numerical weather model data. Geophys. Res. Lett. 2006, 33. [CrossRef]

28. Beutler, G.; Bockmann, E.; Gurtner, W.; Huobler, U.; Mervart, L. Extended orbit modeling techniques at the CODE processing center of the International GPS Service for geodynamics (IGS): Theory and initial results. Eur. Respir. J. 1994, 7, 1350-1364.

29. Wessel, P.; Smith, W.H.F. New, improved version of generic mapping tools released. EOS Trans. AGU 2006, 79, 579. [CrossRef]

30. Sośnica, K.; Thaller, D.; Dach, R.; Steigenberger, P.; Beutler, G.; Arnold, D.; Jäggi, A. Satellite laser ranging to GPS and GLONASS. J. Geod. 2015, 89, 725-743. [CrossRef]

31. Pearlman, M.R.; Degnan, J.J.; Bosworth, J.M. The International Laser Ranging Service. Adv. Space Res. 2002, 30, 135-143. [CrossRef]

32. Phillips, A.H. Geometrical Determination of PDOP. Navigation 1984, 31, 329-337. [CrossRef]

33. Parkinson, B.W.; Enge, P.; Axelrad, P.; Spilker, J.J., Jr. Global Positioning System: Theory and Applications, Volume II. AIAA 1996, 38, 99-102.

34. Wen, Y.L.; Liu, Q.X.; Zhu, J.; Liao, Y. The effect of TT\&C deployment on the regional satellite navigation system. J. Natl. Univ. Def. Technol. 2007, 1, 1-6. [CrossRef]

35. Yang, Y.X.; Wen, Y.L. Synthetically Adaptive Robust Filtering for Satellite Orbit Determination. Sci. China Earth Sci. 2004, 47, 585-592. [CrossRef]

36. Zhang, L.P.; Dang, Y.M.; Xue, S.Q.; Wang, H.; Gu, S.Z.; Wang, C.Y. The Optimal Distribution Strategy of BeiDou Monitoring Stations for GEO Precise Orbit Determination. Lect. Notes Electr. Eng. 2015, 340, 153-161.

37. Arnold, D.; Meindl, M.; Beutler, G.; Dach, R.; Schaer, S.; Lutz, S.; Prange, L.; Sośnica, K.; Mervart, L.; Jäggi, A. CODE's new solar radiation pressure model for GNSS orbit determination. J. Geod. 2015, 89, 775-791. [CrossRef]

38. Zhang, X.H.; He, X.Y. Performance analysis of triple-frequency ambiguity resolution with BeiDou observations. GPS Solut. 2016, 20, 1-13. [CrossRef]

39. Paziewski, J.; Sieradzki, R. Integrated GPS+BDS instantaneous medium baseline RTK positioning: Signal analysis, methodology and performance assessment. Adv. Space Res. 2017. [CrossRef]

40. Odolinski, R.; Teunissen, P.J.G. Single-frequency, dual-GNSS versus dual-frequency, single-GNSS: A low-cost and high-grade receivers GPS-BDS RTK analysis. J. Geod. 2016, 90, 1255-1278. [CrossRef] 
41. Odijk, D.; Nadarajah, N.; Zaminpardaz, S.; Teunissen, P.J.G. GPS, Galileo, QZSS and IRNSS differential ISBs: Estimation and application. GPS Solut. 2016, 21, 439-450. [CrossRef]

42. Paziewski, J.; Sieradzki, R.; Wielgosz, P. Selected properties of GPS and Galileo-IOV receiver intersystem biases in multi-GNSS data processing. Meas. Sci. Technol. 2015, 26, 095008. [CrossRef] 